\title{
The North American Lotus (Nelumbo lutea Willd.); Sacred food of the Osage People
}

\author{
Daniel C. Swan
}

\section{Research}

\begin{abstract}
The North American Lotus (Nelumbo lutea Willd.) is well documented as an important food plant among the $\mathrm{Na}-$ tive people of North America. This paper presents ethnographic and historic evidence of its past veneration by the Osage Indians of Oklahoma as a sacred food and a symbol of their desire for health and long life, particularly for their children. Today N. Iutea has become a prominent traditional food among the Osage and an important culinary element in contemporary Osage cultural identity.
\end{abstract}

\section{Introduction}

The Osage Indians of Oklahoma are among many tribes in North America that used the North American lotus (Nelumbo lutea Willd.) as a seasonal food source. Among the Osage, this plant assumed a sacred status and continues to be an important culinary element in contemporary Osage cultural identity. In the Osage language Nelumbo lutea is called Tse'-wa-the and in English they refer to the plant as Yonkapins, a common folk name for $N$. lutea. An Osage friend, Geoff Standing Bear, introduced me to the plant in 1983, when he treated me to lunch at the Ha-Pah-Zhu-Tse (Red Corn) Restaurant in Pawhuska Oklahoma. Under the leadership of Raymond Red Corn Jr. the family established a successful eatery that featured traditional Osage foods served by waitresses wearing aprons adorned with Osage ribbon-work designs in a décor dominated by historic photographs with Osage war dance songs playing softly in the background. Among the dishes on the menu that particular day was Yonkapins in beef broth. Geoff told me that Yonkapins are a traditional food of the Osage people and he was taught that they are "good for the heart." I lived in the Osage community between 1984 and 1991 and had the occasion to enjoy Yonkapins at Red Corn's café and at various community dinners. During the intervening period I have maintained a close relationship with the Osage community and have observed that although Tse'-wa-the are less frequently encountered at community dinners and events they continue to be an important traditional food among the Osage people. In 2009 Yonkapins were served at the Committee Dinner during the annual llonshka ceremonials in the Pawhuska District (Figure 1).

Nelumbo lutea is a member of Nelumbonaceae, the lotus lily family, under the class Equisetopsida and sub class Magnoliidae, and it is the only lotus native to North America (Tricker 1916:2117, USDA 2009). The plant itself is perennial, growing primarily in the summer mainly through rhizomes and can rapidly cover an area with an average growth of .23 feet per day (Hall 1944:746). Its range includes ponds, slow streams, marshes and lakes in the central and eastern United States with the northern most barriers being the Great Lakes (Small 1933:540).

Nelumbo lutea has a long history of usage in Native North America as an important food resource. There is evidence

\section{Correspondence}

Daniel C. Swan, Department of Ethnology, Sam Noble Oklahoma Museum of Natural History and Department of Anthropology, University of Oklahoma, 2401 Chautauqua Avenue, Norman, Oklahoma 73072. U.S.A.

dcswan@ou.edu

Ethnobotany Research \& Applications 8:249-253 (2010)

Published: November 22, 2010 
that the plant was propagated and disbursed by Native communities in the southeastern United States prior to European contact (Tricker 1916: 2118). The two major resources obtained from the plant were its seeds and tuberous rhizomes. The immature seeds have a chestnut nutlike flavor when eaten raw and mature seeds can be hulled and added to soups as a thickener or roasted and ground to provide flour for flat bread and porridge. The most common usage of $N$. lutea as a food source involves the use of the rhizome of the plant as a starchy vegetable. It is identified in the ethnographic record as a valuable winter resource with large quantities of the tubers gathered, cut laterally into roughly one inch pieces and then strung and dried for later consumption (La Flesche 1932:160; Moerman 1998:353). Analysis of both species of Nelumbo supports its value as a high starch $(31.2 \%)$ vegetable and a good source of Vitamin C, Calcium and Potassium (Kendler et al. 1989:496, Mukherjee et al. 2009:418).

\section{The Osage Case: Ethnographic and historic evidence}

Osage sources indicate that the roots of $N$. lutea were harvested in the fall of the year (Fig. 2). This would coincide with the largest root size, at the end of the active growing season. Community elder Preston Morrell succinctly reports the harvesting process and cooking method:

[These Yonkapins] they're good now, in the fall, just before this cold comes. The water is kind of low in all these lakes. You take your shoes off and you find them with your feet. That mud is soft and you go down in it a ways and you hit them. You reach

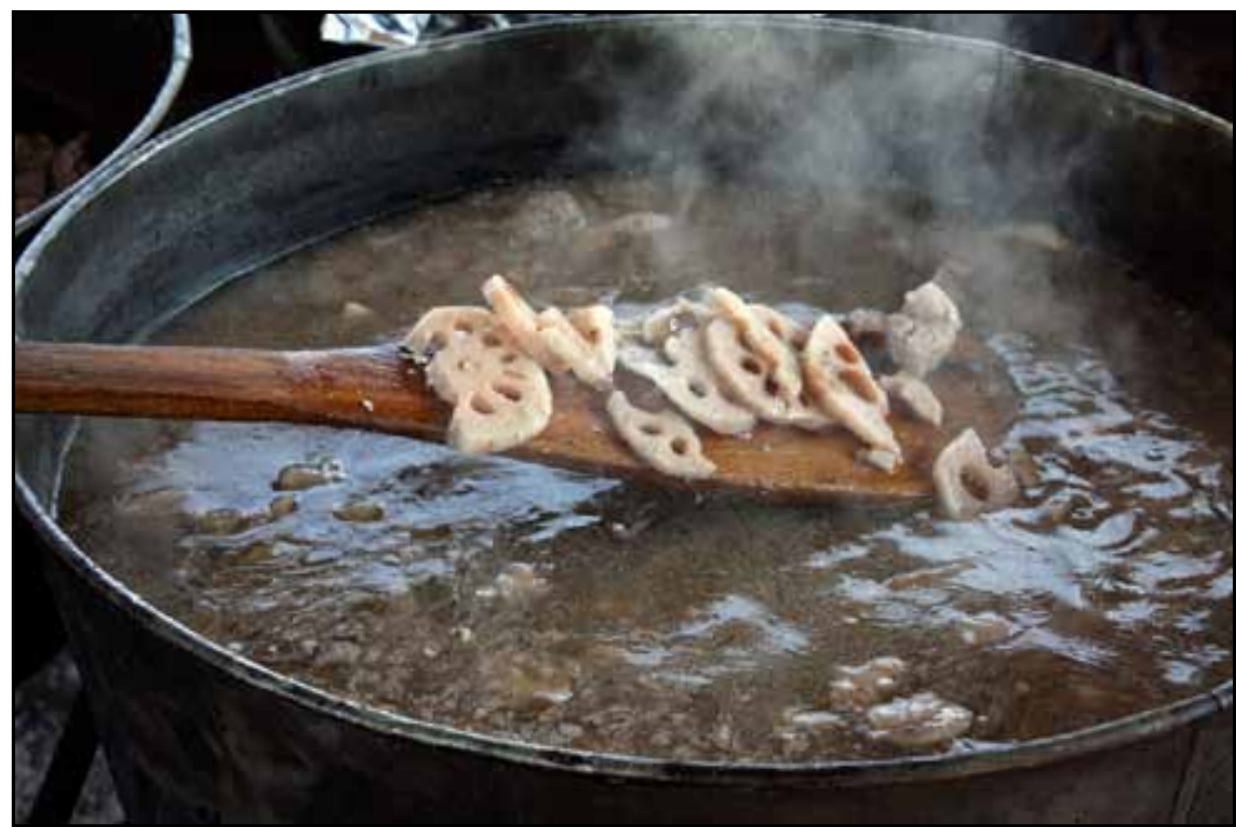

Figure 1. Tse'-wa-the with Beef, Pawhuska District, I-lon-shka Committee dinner, Saturday, June 27, 2009. Photo by Shannon Shaw. Courtesy of The Osage News. down and get them and break them off. You take them home and they clean them, get them real clean put them in hot water and put a piece of pork in there and let them boil. That's good eating boy, with a piece of fry bread. That's one of our main dishes, real Osage Indian dish. (Morrell 1994)

Mr. Morrell also provided additional rationale for a late fall harvest in that the snakes are "asleep" by then. To be safe it was customary to harvest Tse'-wa-the using two people, one to wade into the water and dig the roots and one to gather and wash the roots when they were tossed ashore. This second person also kept a keen eye out for snakes (Maker 1968, Morrell 1994).

Melvin Gilmore (1991:27) reports that among the Osage, Omaha and perhaps other groups in the Dhegian Siouan language family, $N$. lutea was one of a class of plants that assumed "mystical" status. An examination of the Osage religious rituals recorded by Francis La Flesche in the early 20th century (La Flesche 1921, 1925, 1928) reveals a complex symbolic system in which each of the clans (patrilineal social units) of the Osage people possessed several life symbols that represented the ultimate goal of the Osage people--to attain old age and to see their children achieve a long life. Nelumbo lutea assumed the status of a life symbol among the Osage, one of the highest designations that natural phenomena achieved in the cosmology of the Osage people. Nelumbo lutea was one of the life symbols of the In-gthon-ga, or Puma, clan. Taken collectively these life symbols represent a complex set of symbolic relationships that in turn invoke sets of ceremo-

nial and social behaviors to assure the continued existence and prosperity of the Osage (Bailey 1995: 35, 40-42). In 1921 La Flesche reported approximately forty life symbols for the twenty-four clans of the Osage and it is clear that this count is less than definitive. These life symbols were comprised of seventeen animals, sixteen plants, five celestial bodies or weather phenomena, and two objects of material culture (La Flesche 1921: 601).

As a life symbol of the Osage people $N$. lutea is prominent in the ritual narratives recorded by La Flesche in the early 20th 


\section{Swan - The North American Lotus (Nelumbo lutea Willd.); Sacred food of the 251 Osage People}

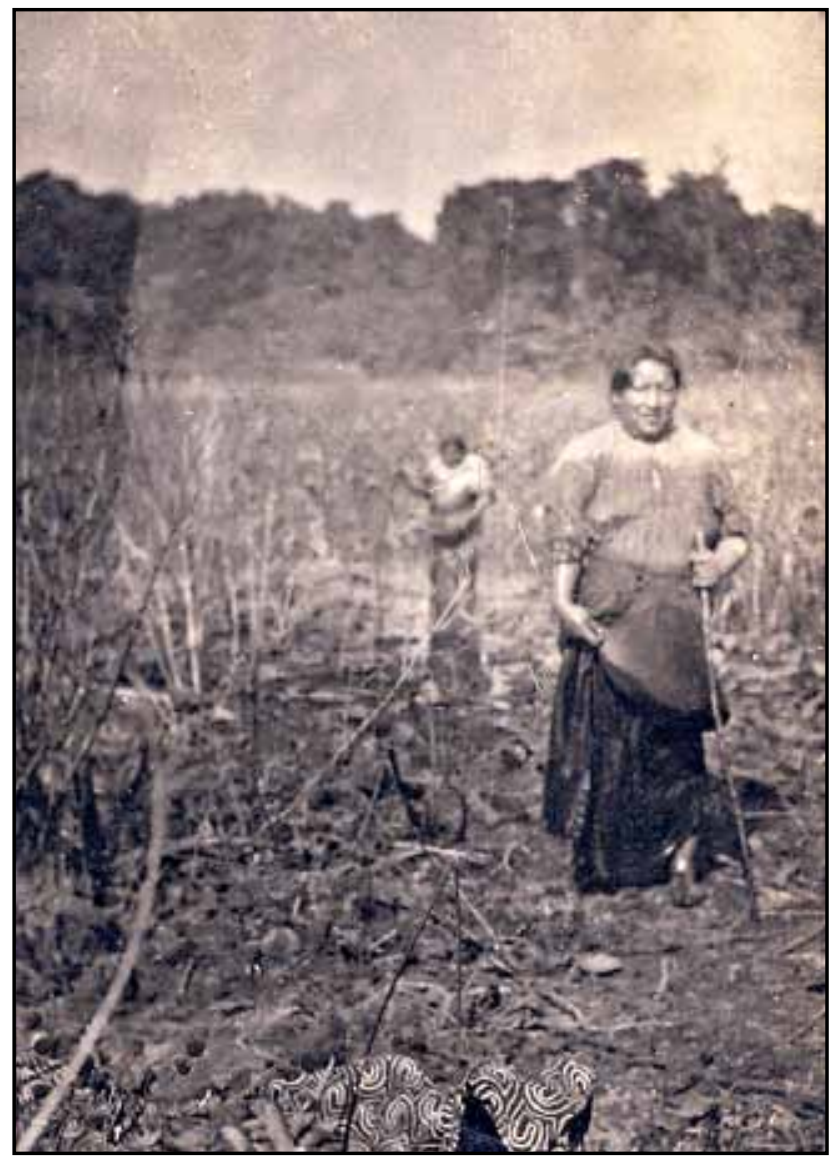

Figure 2. Mrs. Grace Abbott and unidentified woman harvesting Tse'-wa-the. Circa 1920's. Note harvested tubers in foreground and the pole (willow?) possessed by both women. Courtesy of the Osage Tribal Museum.

century. In the Rite of the Chiefs, an allegorical examination of the formation of the tribe and the development of its civil and military organizations, $N$. lutea is identified as a plant "which is dedicated to use as a sacred food in the bringingup of the little ones" (La Flesche 1921:55). In the Rite of Vigil (La Flesche 1925) one of a series of war rites invoked for the defense of the Osage people, $N$. lutea is mentioned during the instructions to the wife of the Singer, an important ceremonial position. In this passage the woman gains instruction in the ceremonial gathering of $N$. lutea:

The Tse'-wa-the (water chinquapin) with which you feed your children is also a sacred food and should be gathered with proper ceremony. It is a symbol of life. When you set a day to go and gather this food, aim to rise with the sun and paint the parting of your hair red. The red line represents the path of the god of day and the paths of all living things which converge toward you and give to you and your children both food and clothing. When you come to the lake where you are to gather the Tse'-wa-the cut a willow pole. The willow is a tree that never dies and is a symbol of life. When you have cut the pole remember to say: 'My grandfathers bade to me to say: "This is to be my staff." Upon entering the water to begin your work, take from the bottom of the lake a bit of mud and touch your head and body with it. This act is your prayer to the earth. Then proceed to dig. When you have secured the first root, rub your arms and body with it, that you may receive the blessing of life, and then throw it back into the water and remember to say: 'My grandfather bade me to do this act. (La Flesche 1925: 129)

This narrative provides clear example of the manners in which numerous natural elements--the Sun, yellow lotus and willow--interact with one another in both pragmatic and symbolic contexts. A number of the actions and practices described in this passage find expression within contemporary Osage idiom, including the conduct of sacred and important business at dawn, the painting of the part in one's hair and the use of natural objects to convey blessings. In a wider comparative context, this account echoes the solemnity with which other native peoples harvest culturally important plants (Jackson 2002: 4).

The special significance of $N$. lutea, and a related group of plant foods is more fully revealed in a later section of the Rite of the Vigil (La Flesche 1925: 129-130). In discussing the singing of the Deer Songs during the ceremony La Flesche notes that they are:

...next to the sections relating to the search for and the finding of the roots from the four plant foods that were consecrated for the use of the people as sacred foods. These four plants, namely Nelumbo lutea, Apios apios [now Apios americana Medik.], Sagittaria latifolia, and Falcata comosa [now Amphicarpaea bracteata (L.) Fernald], as well as the deer afforded the people a steady supply of food, and were, for that reason, particularly mentioned in the rituals of the great war rites. The people regarded these food plants and the deer not merely as natural food products but also necessary to the very existence of the tribe itself, therefore the warriors were depended upon to hold with all their strength and valor against invasions by unfriendly tribes the land that yields such products.

An interesting addition to the above information can be found in the Osage Child Naming Rite where three of the aforementioned root foods are paired with a particular species of wild game in what translates to "companions," intended to be used together as food. The pairings are $N$. lutea (yonkapin) with the young buffa- 
lo bull, $A$. americana (Indian potato) with the dark-horned deer, and $A$. bracteata (ground bean) with the turkey (La Flesche 1928:111-112)). It remains for additional research to determine if these interesting pairings of animal and plant resources might reflect environmental or nutritional agendas cast within the symbolic relationships of plants and animals in Osage cosmology.

\section{Conclusion}

Although the ingredients and recipes of Osage culinary traditions have evolved over time, a consistent factor in Osage feasting behavior is the precept that food is a sacred affair, with the sustenance of life considered the ultimate gift in Osage society. In the inventory of wild plant resources that were once indispensible components in the lives of the Osage people Tse'-wa-the is one of the few that endures. It is a food source of tremendous symbolic importance, whose gathering, preparation and cooking are reserved for the most important of community occasions, including the feasts associated with the committee dinners of the Ilonshka Districts, services of the Native American Church, child naming events, and funerals (Bailey 2004:145, Swan 2004a:117, 2004b:162). Although the ceremonies and rituals of the Osage tribal religion are no longer performed and Tse'-wa-the is no longer venerated as a life symbol, the dish itself and the effort involved to bring it to the table continues to be respected as a gift of life, symbolic of the prayers and hopes of the Osage community for the wellbeing and growth of their children.

\section{Acknowledgements}

The author would like to recognize the support of the Osage community in this endeavor, particularly the assistance of Geoffrey Standing Bear and Preston Morrell. I would also like to recognize Philip Soltero for research assistance and Shannon Shaw, Osage Nation News and Rhonda Kohnle, Osage Tribal Museum for their generous sharing of photographs. Appreciation is extended to Jason B. Jackson for commenting on an earlier draft of this paper.

\section{Literature Cited}

Bailey, G.A. 1995. Editor of The Osage and Invisible World of the Osage Indians: From the works of Francis La Flesche. University of Oklahoma Press. Norman, Oklahoma.

Bailey, G.A. 2004. The richest people in the world. Pp. 137-155 in Art of the Osage. Edited by G. Bailey \& D.C. Swan. University of Washington Press. Seattle, Washington.
Gilmore, M.R. 1991. Uses of Plants by the Indians of the Missouri River Region. Enlarged edition. University of $\mathrm{Ne}-$ braska Press, Lincoln, Nebraska.

Hall, T.F. \& W.T. Penford. 1944. The biology of the American lotus, Nelumbo lutea (Willd.) Pers. American Midland Naturalist 31(3):744-758.

Jackson, J.B. 2002. Spirit medicine: Native American uses of common everlasting (Psedognaphalium obtusifolium) in Eastern North America. Occasional Papers, Sam Noble Oklahoma Museum of Natural History 13:1-17.

Kendler, B.S. \& D.J. Pirone. 1989. Familiarizing students with some edible and poisonous wild plants. The American Biology Teacher 51(8):463-471.

La Flesche, F. 1921. The Osage tribe: Rite of the chiefs; Sayings of the ancient men. Pp. 47-59 in 36th Annual Report, Bureau of American Ethnology. U.S. Government Printing Office, Washington, D.C.

La Flesche, F. 1925. Rite of vigil. Pp. 60-61 in 39th Annual Report of the Bureau of American Ethnology. U.S. Government Printing Office, Washington, D.C.

La Flesche, F. 1928. The Osage tribe: Two versions of the child-naming rite. Pp. 29-30 in 43rd Annual Report of the Bureau of American Ethnology. U.S. Government Printing Office, Washington, D.C.

La Flesche, F. 1932. A Dictionary of the Osage Language. Bulletin 109, Bureau of American Ethnology. U.S. Government Printing Office, Washington, D.C.

Maker, M. 1968. Interview transcription. Interview number T-342. Interviewed by L. Maker; Transcribed by B. Paukei. Doris Duke Oral History Collection, Western History Collections, University of Oklahoma. Norman, Oklahoma.

Moerman, D.E. 1998. Native American Ethnobotany. Timber Press, Portland, Oregon.

Morrell, P. 1994. Oral History interview by D.C. Swan. Volume 1, Track 2. Tulsa, Oklahoma. Author's private collection.

Mukherjee, P.K., D. Mukherjee, A.K. Maji, S. Rai \& M. Heinrich. 2009. The sacred lotus (Nelumbo nucifera)Phytochemical and therapeutic profile. Journal of Pharmacy and Pharmacology 61:407-422.

Small, J.K. 1933. Manual of the Southeastern Flora. University of North Carolina Press, Chapel Hill, North Carolina. 


\section{Swan - The North American Lotus (Nelumbo lutea Willd.); Sacred food of the 253 Osage People}

Swan, D.C. 2004a. The Osage peyote religion. Pp. 108135 in Art of the Osage. Edited by G. Bailey \& D.C. Swan. University of Washington Press. Seattle, Washington.

Swan, D.C. 2004b. Osage dancing societies and organizations. Pp. 156-194 in Art of the Osage. Edited by G. Bailey \& D.C. Swan. University of Washington Press, Seattle, Washington.
Tricker, W. 1916. Nelumbo. Pp. 2117-2118 in The Standard Cyclopedia of Horticulture 4. Edited by L.H. Bailey. Macmillan Company, London.

USDA National Resource Conservation Service. 2009. Nelumbo lutea Willd. in Plants Database. http://plants. usda.gov/java/nameSearch?keywordquery=nelumbo+lut ea\&mode=sciname\&submit. $x=0 \&$ submit. $y=0$ 
